\title{
Impact Of Combined Lumbar Traction with Cervical Traction In Chronic Lumbar Disc Herniation
}

\author{
Al-Qudah, Mohammad Khalid \\ ${ }^{1}$ Department of Sport Rehabilitation, Faculty of Sports Science, Mutah University. PO Box 7 Mutah- Al- \\ Karak, Hashemite Kingdom of Jordan. \\ Tel,:+962790201815; E-mail: yes22r@yahoo.co.uk
}

Article History: Received: 31 January 2021; Accepted: 27 February 2021; Published online: 5 April 2021

\begin{abstract}
Background: Traction Is Part Of The Evidence Based Manual Physical Therapy Management Due To Its Mechanical Nature. The Efficacy Of Lumbar Traction (LT) Has Been Established, LT As The Most Used Method Of Spinal Decompression Therapy (SDT) Reduces The Intradiscal Pressure And Vertically Increases The Intervertebral Space And Restore Disc Height Allowing Nutrients And Oxygen Supply To The Disc. While Lt Had Recently Been Used As A Conservative Treatment For Chronic Lumbar Disc Herniation (CLDH), Combined Lumbar Traction With Cervical Traction (CLTCT) As One Intervention Which Has Been Suggested By (Al-Qudah, M.K) Was Used As A Part Of Rehabilitative Program In Patients With CLDH. Therefore, The Effectiveness Of CLTCT Separately At Any Other Interventions Remains Absolutely Unclear And Uncertain.

Objective: The Aim Of The Presented Work Is To Identify The Effectiveness Of CLTCT [(Positional Sustained Lumbar Traction (PSLT) Combined With Mechanical Sustained Cervical Traction (MSCT) As One Intervention] On Patients With Moderate (L4-L5) (L5-S1) CLDH, And To Compare CLTCT With Traditional Mechanical Lumbar Traction (MLT).

Methods: In This Study, Twelve Outdoor Male Patients Diagnosed With Magnetic Resonance Imaging (MRI), Had Accepted To Participate The Study. They Were Chosen From Al-Karak Governmental Hospital. Subjects Were Divided Randomly In To Two Groups, Experimental Group (N=6) Performed Cupping Massage (CM), CLTCT And Core Stabilization Exercise (CSE), While The Control Group (N=6) Performed CM, MLT And CSE. All Subjects Were Advised To Perform The CSE Three Times Daily As A Home Program In Addition To One Set During Each Session Under The Therapist Supervision. All Subjects Had Exposed (18) Sessions For (6) Weeks. The Results Were Analyzed Using The SPSS System.

Results: Indicates That There Was Statistically Significant Difference Between The Pre And Post Measurements In Both Groups In Favor Of The Post Measurements In Term Of Pain And Disability. Also Results Indicate That There Was Statistically Significant Difference Between The Groups In Favor Of Experimental Group.

Conclusions: The Present Study Demonstrates That The Use Of CLTCT Has A Positive Effect On Patients With CLDH More Than MLT.
\end{abstract}

Keywords: Chronic Lumbar Disc Herniation, Combined Lumbar Traction with Cervical Traction, Pain Score, Disability Index.

\section{Introduction}

Low back pain (LBP) is often work-related and is commonly observed among world population. LBP occurs mostly due to Lumbar Disc Herniation (LDH) [13]. Eighty percent of adults experience lumbar pain at least once in their lifetime, and $80 \%$ of structures causing lumbar pain are related to intervertebral discs [11]. Ninety five percent $95 \%$ of the herniated lumbar disc occurs at the L4-L5 and L5-S1 spinal levels, especially in 25 to 55 years of age [22]. Chronic Lumbar Disc Herniation (CLDH) is a common clinical problem that is associated with gradual accumulative pain, functional limitations and persistent disability, where pain radiates down the back of the thigh into the leg [2]. This damage is caused by compression of the nerve roots which exit the lumbar spine levels [11]. Treatment of CLDH is widely varied between surgical and conservative methods. Conservative treatments include medication, exercise therapy, and physical and rehabilitation methods[11]

Therapeutic methods are used in CLDH treatment in gradual manner. Thermotherapy, such as Hot packs, Electrotherapy, Massage and Cupping Massage are used to start treatment sessions to restore blood circulation activity, allowing nutrients to reach tissues, relax muscle tone, decrease nerve endings sensation and rise pain threshold $[1,2,3,15]$. Now a day, Cupping massage (CM) as an alternative to massage is widely used $[1,2,3]$, especially in light of the emerging Corona-19 pandemic, which makes it an ideal option instead of massage to prevent friction and hand contact with patients. Previous studies has established the effectiveness of CM in term of releasing pain, disability and restoring range of motion $(\mathrm{ROM})[1,2,3,27,25,16]$, and also rising low back temperature, So, it could be beneficial as some deep therapeutic massage techniques $[1,2,3,16]$. 
Spinal Decompression Therapy (SDT) is widely used method. Lumbar Traction (LT) appears to be one of the most used methods among SDT [8]. LT decreases the pressure by delivering nutrients and oxygen to the intervertebral disc and vertically increase intervertebral space and restore disc height, increases its hydration and reduces pressure on the nerve root by removing the force applied to the vertebral pulp[2,3,19,20].

While the advancements in traction equipment are needed to ensure their effectiveness in clinical situations [8], the advancement in creative methods of SDT are extremely more needed. Various methods of LT had recently been used as a conservative treatment for CLDH, but the Combination of Lumbar Traction with Cervical Traction (CLTCT) as one intervention which has been suggested by Al- Qudah, was used as a part of rehabilitative Program in patients with CLDH [2]. Therefore, the effectiveness of CLTCT separately at any other interventions remains absolutely unclear and uncertain.

Therapeutic exercise is one of the most common conservative treatments, which mostly include core stabilization exercises (CSE). It can assist the activation of the deep fibers of lumbar Multifidus muscle through low loaded isometric activity [13,21]. CSE seemed to decrease pain intensity and improve functional ability in specific low back pain (LBP) when added to the routine physical therapy[8].

Effectiveness of CM, SDT with CSE has been clinically approved[2], but the clinical effectiveness of CLTCT separately still uncertain. Therefore, the aim of the current study was to assess the efficacy of CLTCT, and to compare CLTCT with Traditional MLT in patients with CLDH.

\section{Methodology}

\subsection{Participants}

This study is a randomized controlled trial that aimed to assess the efficacy of CLTCT, and to compare CLTCT with MLT in patients with moderate CLDH. Twelve outdoor male patients $(n=12)$ (mean age: 47.75) from AlKarak Governmental Hospital From $15^{\text {th }}$ Of December To $26^{\text {th }}$ January 2021. Subjects presented with (L4-L5) (L5-S1) confirmed by MRI report with radiating symptoms for over three months were included in the study. Subjects who had infection with COVID-19 or had osteoporosis, vertebral fracture, previous back surgeries, history of prolonged use of corticosteroids, artificial disc or other spinal implants, malignancy, cauda equina lesions, in addition to LBP due to other conditions such as sacroiliac joint pathology or muscle tightness or even with BMI over 30 were excluded from the study. All the subjects signed a written informed consent form prior to their participation in the study. The study was conducted in Laboratory of Physiology at Sport Rehabilitation Department -Mutah University. The study was approved by the ethical committee of Ministry of Health and Health Care, Amman, The Hashemite Kingdom Of Jordan.

\subsection{Experimental design}

Subjects who fulfilled the criteria were assigned randomly to two groups, Control group (n=6) (mean age= $47.8333 \pm 2.13698)$, and Experimental group $(n=6)($ mean age $=47.6667 \pm 2.42212)$. Subjects in the Control group received CM, MLT and CSE, the subjects in Experimental group received CM, CLTCT and CSE. Subjects in both groups received 18 sessions of treatment for a period of 6 weeks. It is clearly seen that interventions are similar in both groups, except the used SDT method, where experimental group received SDT via CLTCT, while control group received SDT via MLT. Outcome measures were assessed before and after the treatment period to measure pain intensity and functional disability with the scales outlined below.

\subsection{Outcome measures}

\subsubsection{Numerical Rating Scale (NRS)}

To estimate the pain score through selecting out of 10 , the number that best describes the intensity of pain, where 0 indicates "no pain" and 10 indicates "the worst possible pain".

Functional disability scale assessed the influence of LBP on daily activities. The questionnaire contains ten questions addressing different aspects of daily living tasks. Each question scored from 0 to 5, higher value describes greater disability. The total scores were expressed in percentage. Al-Qudah \& Al-Jazzazi [2] recommended to ignore section No.8 that is measuring pain connected with Sexual abilities, during answering ODI in bedouins Societies. Subjects may completely refuse to answer the whole Questionnaire due to their bedouins eastern cultural restrictions. So, researcher had printed out ODI without section No.8.

\subsection{Interventions}




\subsubsection{Cupping Massage(CM)}

Simi prone position was used with special pillows for supporting the torso. Sterilization, lubrication and soft full back, shoulders and neck CM were used for 10 minutes. A disposable silicon cups measuring $3 \mathrm{~cm}$ and $6 \mathrm{~cm}$ was used to fit the back, shoulders and neck area, quietly as described by Al-Qudah \& Al-Jazzazi [2]. Both groups received similar CM program.

\subsubsection{Spinal Decompression Therapy(SDT)}

\subsubsection{Mechanical Sustained Lumbar Traction(MSLT)}

Control group has conduct MSLT via a medical mobile Lumbar Traction device (Ospine-YQAH-1) as a method of SDT, it was conducted from supine position, thighs were elevated upon special pillows to reach comfort, where the formed angle between trunk and thighs was (130-140) degree. Each subject in the control group received approximately 20 minutes of MSLT. The procedure amid to execute a nonsurgical spinal decompression. Forceful physical activities that compress the disc were prevented. CSE was described and conducted at the beginning of the second phase (third week).

\subsubsection{Combined Lumbar Traction With Cervical Traction (CLTCT)}

Experimental group has conduct CLTCT [ Supine Mechanical Sustained Cervical Traction (MSCT) via medical mobile cervical traction devise (Ospine-NTD-500), then immediately a Supine Positional Sustained Lumbar Traction (PSLT) (Hip Flexion) (HP)] was applied, then the hip was manually extra pulled and rotated, then time recording started. This procedure was conducted as a method of SDT, and amid

to execute a nonsurgical spinal decompression. Cervical Decompression force was manually controlled and raised gradually in the terminal part of the treatment. Each subject in the study received approximately 20 minutes of CLTCT.

The treatment program in experimental group included 3 phases:

- $\quad$ Phase 1: The first two weeks, 6 sessions: before the beginning, during MSCT pressure was raised gradually from 16-20 PSI, with Maximum HF as PSLT.

- $\quad$ Phase 2: The second two weeks, 6 sessions: before the beginning, during MSCT pressure was raised gradually from 16-21 PSI, with Maximum HF as PSLT.

Phase 3: The last two weeks, 6 sessions: before the beginning, during MSCT pressure was raised gradually from 16-22 PSI, with Maximum HF as PSLT.

Forceful physical activities that compress the disc were prevented. CSE was described and conducted at the beginning of the second phase (third week).

\subsubsection{Core stabilization exercises(CSE)}

At the beginning of the third week, both groups conducted CSE program including activation of Lumbar Multifidus and Transverses Abdominis muscles from crook lying, bridging, and quadruped position as described by Puntumetakul [26], for 10 repetitions with 10 seconds hold in each repetition. Participants in the two groups were asked to perform the CSE three times daily as a home program in addition to one set during each session under the therapist supervision. Both groups received similar CSEprogram.

\section{Results}

\subsection{Statisticalanalysis}

Statistical analyses were performed using the SPSS software version 22. Variables were presented Means, Standard Deviations, Mean Ranks and Sum Of Ranks for non- normally distributed quantitative data. Differences between groups were analyzed with Mann-Whitney U test for quantitative data. Wilcoxon test was used to compare the change in outcome measures between baseline and immediately after the treatment. A $\mathrm{p}$ value of less than 0.05 was considered to show statistically significant results. 
Fifteen male patients were randomly divided into two groups, control $(n=7)$ or experimental group $(n=8)$. Of the 15 participants, 12 completed the 6-week study period. One patient of the control group and Two of experimental group dropped out of the study. Twelve subjects completed the intervention (mean age: 47.75) in the both control and experimental groups: Control group $(n=6)$ (mean age $=47.833 \pm 2.13698$ ), and Experimental group $(n=6)$ (mean age $=47.66 \pm 2.422)$. Demographic and baseline characteristics of the subjects mentioned in Table1.

Table No. (1) Baseline characteristics of participants who completed the study

\begin{tabular}{|c|c|c|c|c|c|c|c|c|c|}
\hline & Group & $\mathrm{N}$ & Mean & $\begin{array}{c}\text { Std. } \\
\text { Deviation }\end{array}$ & $\begin{array}{l}\text { Mean } \\
\text { Rank }\end{array}$ & $\begin{array}{l}\text { Sum of } \\
\text { Ranks }\end{array}$ & $\begin{array}{c}\text { Mann- } \\
\text { Whitney U }\end{array}$ & $\mathrm{Z}$ & $\mathrm{p}$ \\
\hline Age & $\begin{array}{l}\text { Control } \\
\text { Experimental } \\
\text { Total }\end{array}$ & $\begin{array}{r}6 \\
6 \\
12\end{array}$ & $\begin{array}{l}47.8333 \\
47.6667\end{array}$ & $\begin{array}{l}2.13698 \\
2.42212\end{array}$ & $\begin{array}{l}6.33 \\
6.67\end{array}$ & $\begin{array}{l}38.00 \\
40.00\end{array}$ & 17.000 & .162 & 871 \\
\hline Height & $\begin{array}{l}\text { Control } \\
\text { Experimental } \\
\text { Total }\end{array}$ & \begin{tabular}{r|}
6 \\
6 \\
12 \\
\end{tabular} & $\begin{array}{l}1.7550 \\
1.7517\end{array}$ & $\begin{array}{l}.01871 \\
.02483\end{array}$ & \begin{tabular}{l|}
7.08 \\
5.92
\end{tabular} & $\begin{array}{l}42.50 \\
35.50\end{array}$ & 14.500 & .569 & 569 \\
\hline Weight & $\begin{array}{l}\text { Control } \\
\text { Experimental } \\
\text { Total }\end{array}$ & \begin{tabular}{r|}
6 \\
6 \\
12 \\
\end{tabular} & $\begin{array}{l}81.1667 \\
81.6667\end{array}$ & $\begin{array}{l}6.36920 \\
6.97615\end{array}$ & \begin{tabular}{l|}
5.92 \\
7.08
\end{tabular} & $\begin{array}{l}35.50 \\
42.50\end{array}$ & 14.500 & .562 & 574 \\
\hline $\begin{array}{l}\text { Body Mass } \\
\text { Index } \\
(\text { BMI) }\end{array}$ & $\begin{array}{l}\text { Control } \\
\text { Experimental } \\
\text { Total }\end{array}$ & $\begin{array}{r}6 \\
6 \\
12\end{array}$ & $\begin{array}{l}26.3726 \\
26.6110\end{array}$ & $\begin{array}{l}2.29179 \\
2.15814\end{array}$ & $\begin{array}{l}6.33 \\
6.67\end{array}$ & $\begin{array}{l}38.00 \\
40.00\end{array}$ & 17.000 & .160 & 873 \\
\hline $\begin{array}{l}\text { Pain Score } \\
\text { pre }\end{array}$ & $\begin{array}{l}\text { Control } \\
\text { Experimental } \\
\text { Total }\end{array}$ & \begin{tabular}{r|}
6 \\
6 \\
12 \\
\end{tabular} & $\begin{array}{l}5.0000 \\
5.3333\end{array}$ & $\begin{array}{l}.89443 \\
.81650\end{array}$ & \begin{tabular}{l|}
5.83 \\
7.17
\end{tabular} & $\begin{array}{l}35.00 \\
43.00\end{array}$ & 14.000 & .682 & 495 \\
\hline $\begin{array}{l}\text { Disability Score } \\
\text { - pre }\end{array}$ & $\begin{array}{l}\text { Control } \\
\text { Experimental } \\
\text { Total }\end{array}$ & $\begin{array}{r}6 \\
6 \\
12\end{array}$ & $\begin{array}{l}54.6667 \\
55.8333\end{array}$ & $\begin{array}{l}5.08593 \\
3.81663\end{array}$ & $\begin{array}{l}6.42 \\
6.58\end{array}$ & $\begin{array}{l}38.50 \\
39.50\end{array}$ & 17.500 & .081 & 935 \\
\hline
\end{tabular}

* statistically significant $\mathrm{p}$ value $\leq 0.05$ ( Mann-Whitney Test $\mathrm{U}$ )

\section{2.}

\section{Numerical Rating Scale}

The scores showed a significant change in control group before and after the intervention with difference in Mean Ranks; based on positive ranks $(\mathrm{z}=-2.232)$ where $(\mathrm{P}=0.026)$ Showing 3.50 to -0.00 . The intervention showed an absolute change (Table 2). Similarly, the experimental group showed a significant change before and after the intervention with difference in Mean Ranks; based on positive ranks $(\mathrm{z}=-2.251)$ where $(\mathrm{P}=0.024)$ Showing 5.30 to -0.00 . The intervention showed an absolute change (Table 3). The cores also showed a statistical significant deference between groups after the intervention with difference in Mean Ranks; $(\mathrm{z}=$ -2.676), where $\mathrm{p}=0.007$ (Table 4).

\section{3.}

\section{Oswestry Disability Index(ODI)}

The scores showed a significant change in control group before and after the intervention with difference in Mean Ranks; based on positive ranks $(\mathrm{z}=-2.207)$ where $(\mathrm{P}=0.027)$ Showing 3.5 to -0.00 . The intervention showed an absolute change (Table 2). Similarly in the experimental group there was a significant change before and after the intervention with difference in Mean Ranks; based on positive ranks $(\mathrm{z}=-2.201)$ where $(\mathrm{P}=$ 0.028 ) Showing $3.5-0.00$. The intervention showed an absolute change (Table 3$)$. The scores also showed a statistical significant deference between groups after the intervention with difference in Mean Ranks; $(\mathrm{z}=$ 2.913), where $\mathrm{p}=0.004$ (Table4). 
Table No. (2)

comparison of outcome variables between pre and post measurements for controlgroup

\begin{tabular}{|c|c|c|c|c|c|c|c|c|c|}
\hline Out comes & Pair & Mean & $\begin{array}{c}\text { Std. } \\
\text { Deviation }\end{array}$ & & $\mathbf{N}$ & $\begin{array}{l}\text { Mean } \\
\text { Rank }\end{array}$ & $\begin{array}{l}\text { Sum of } \\
\text { Ranks }\end{array}$ & $\mathbf{Z}$ & $\mathbf{P}$ \\
\hline \multirow[t]{4}{*}{ Pain Score } & Pre & 5.0000 & .89443 & $\begin{array}{l}\text { Negative } \\
\text { Ranks }\end{array}$ & 6 & 3.50 & 21.00 & \multirow[t]{4}{*}{$2.232^{b}$} & \multirow[t]{4}{*}{$\begin{array}{r}.026 \\
*\end{array}$} \\
\hline & Post & 2.1667 & .40825 & $\begin{array}{l}\text { Positive } \\
\text { Ranks }\end{array}$ & 0 & .00 & .00 & & \\
\hline & & & & Ties & 0 & & & & \\
\hline & & & & Total & 6 & & & & \\
\hline \multirow[t]{4}{*}{ Disability Score } & Pre & 54.6667 & 5.08593 & $\begin{array}{l}\text { Negative } \\
\text { Ranks }\end{array}$ & 6 & 3.50 & 21.00 & \multirow[t]{4}{*}{$2.207^{b}$} & \multirow[t]{4}{*}{$\begin{array}{r}.027 \\
*\end{array}$} \\
\hline & Post & 42.6667 & $1.7511 \mathrm{C}$ & $\begin{array}{l}\text { Positive } \\
\text { Ranks }\end{array}$ & 0 & .00 & \multirow[t]{3}{*}{.00} & & \\
\hline & & & & Ties & 0 & & & & \\
\hline & & & & Total & 6 & & & & \\
\hline
\end{tabular}

b. Based on positive ranks

Table No. (3)

comparison of outcome variables between pre and post measurements forExperimental group

\begin{tabular}{|c|c|c|c|c|c|c|c|c|c|}
\hline Put comes & Pair & Mean & $\begin{array}{c}\text { Std. } \\
\text { Deviation }\end{array}$ & & $\mathrm{N}$ & $\begin{array}{l}\text { Mean } \\
\text { Rank }\end{array}$ & $\begin{array}{c}\text { Sum of } \\
\text { Ranks }\end{array}$ & $\mathrm{Z}$ & $\mathrm{P}$ \\
\hline \multirow[t]{4}{*}{ Pain Score } & Pre & 5.3333 & .81650 & $\begin{array}{l}\text { Negative } \\
\text { Ranks }\end{array}$ & 6 & 3.50 & 21.00 & \multirow[t]{4}{*}{$-2.251^{b}$} & \multirow[t]{4}{*}{$024 *$} \\
\hline & Post & .8333 & .75277 & $\begin{array}{l}\text { Positive } \\
\text { Ranks }\end{array}$ & 0 & .00 & .00 & & \\
\hline & & & & Ties & 0 & & & & \\
\hline & & & & Total & 6 & & & & \\
\hline \multirow[t]{4}{*}{ Disability Score } & Pre & 55.8333 & 3.81663 & $\begin{array}{l}\text { Negative } \\
\text { Ranks }\end{array}$ & 6 & 3.50 & 21.00 & \multirow[t]{4}{*}{$-2.201^{b}$} & \multirow[t]{4}{*}{$028 *$} \\
\hline & \multirow[t]{3}{*}{ Post } & 20.6667 & 1.96638 & $\begin{array}{l}\text { Positive } \\
\text { Ranks }\end{array}$ & 0 & .00 & \multirow[t]{3}{*}{.00} & & \\
\hline & & & & Ties & 0 & & & & \\
\hline & & & & Total & 6 & & & & \\
\hline
\end{tabular}

* statistically significant $\mathrm{p}$ value $\leq 0.05$ (Wilcoxon Signed Ranks Test)

b. Based on positive ranks

Table No. (4)

Comparison of outcome variables between Control and Experimental group in post test

\begin{tabular}{|c|c|c|c|c|c|c|c|c|c|}
\hline & Group & $\mathrm{N}$ & Mean & \begin{tabular}{|c|} 
Std. \\
Deviation
\end{tabular} & $\begin{array}{l}\text { Mean } \\
\text { Rank }\end{array}$ & $\begin{array}{l}\text { Sum of } \\
\text { Ranks }\end{array}$ & $\begin{array}{c}\text { Mann- } \\
\text { Whitney U }\end{array}$ & $\mathrm{Z}$ & $p$ \\
\hline $\begin{array}{l}\text { Pain Score } \\
\text { post }\end{array}$ & $\begin{array}{l}\text { Control } \\
\text { Experimental } \\
\text { Total }\end{array}$ & $\begin{array}{r}6 \\
6 \\
12\end{array}$ & $\begin{array}{r}2.1667 \\
.8333\end{array}$ & $\begin{array}{l}.40825 \\
.75277\end{array}$ & $\begin{array}{l}9.08 \\
3.92\end{array}$ & $\begin{array}{l}54.50 \\
23.50\end{array}$ & 2.500 & -2.676 & $* .007$ \\
\hline $\begin{array}{l}\text { Disability Score } \\
\text { _post }\end{array}$ & $\begin{array}{l}\text { Control } \\
\text { Experimental } \\
\text { Total }\end{array}$ & $\begin{array}{r}6 \\
6 \\
12\end{array}$ & $\begin{array}{l}42.6667 \\
20.6667\end{array}$ & $\begin{array}{l}1.75119 \\
1.96638\end{array}$ & $\begin{array}{l}9.50 \\
3.50\end{array}$ & $\begin{array}{l}57.00 \\
21.00\end{array}$ & 000 & \begin{tabular}{|l|}
-913 \\
\end{tabular} & $* .004$ \\
\hline
\end{tabular}

4.

statistically significant $p$ value $\leq 0.05$ ( Mann-Whitney Test $U$ )

Discussion

The aim of the study was to evaluate how Combined Lumbar Traction with Cervical Traction (CLTCT) as one intervention affect pain and disability among patients with CLDH, and to compare CLTCT with Mechanical Lumbar Traction (MLT). 
The results showed that a 6-week of MC and CLTCT with CSE significantly reduced pain and disability in the experimental group. Even though there was a significant improvement in the control group when they applied MC and MLT with CSE, the experimental group was showing significantly better improvement as compared to the control group. It was found that all patients (6 of 6$)$ who suffer from sciatica in the experimental group have relieved their symptoms completely, while 4 out of 6 patients in the control group had their symptoms relieved completely, suggesting that treating the herniated disc and reducing the pressure can prevent or relieve secondary problems such as sciatica and LBP. Also it is suggesting that CLTCT as a new modified method of SDT is the start of Accelerated Rehabilitative programs era.

Cupping Massage (CM) that was used in both groups could relax superficial muscles, increase lower back temperature and increase pain threshold $[1,2,25,16,15]$. On the other hand, CM could facilitate the action of other next treatment modalities [2,3].

Spinal Decompression Therapy (SDT) which was used in experimental group via CLTCT - as a modified method of SDT, and in the control group via Mechanical Lumbar Traction (MLT) - reduces the intradiscal pressure and vertically increases the intervertebral space and restore disc height allowing nutrients and oxygen supply to the disc $[2,13,11,19]$, increases its hydration and reduces pressure on the nerve root by removing the force applied to the vertebral pulp $[13,11,19,20]$, this relief of compression can promote regeneration of diseased disc [7], and therefore the dual mechanical effect of CLTCT may relieve pain secondary to disc hernia and other symptoms more than other SDT modalities such as MLT. CLTCT tracts the vertebral column upward and downward at the same time [2], suggesting that CLTCT reduces the intradiscal pressure effectively more than any other SDT methods, facilitates restoration of all other positive structural and physiological alteration in the affected disc and the whole spinal region.

In addition, the effect of CSE which was used in both groups may provide stability and decrease the risk of subsequent injury through the activation of deep trunk muscles, which is useful in treating the pain, and disability in chronic LBP [2,3,13,11,24,4,5,21].

The results are consistent with prior study of Cupping Massage (CM) in the treatment of CLDH [2], where Cupping was associated with reduction of pain and disability and Range Of Motion (ROM) improvement. Results are also consistent with prior studies of CM in the treatment of nonspecific LBP [3 16], where CM reduce pain and disability. On the other hand, Results are in agreement with prior studies of CM in the treatment of chronic neck pain [27], where CM reduce pain and disability.

The current results are also in agreement with prior studies of Spinal Decompression Therapy (SDT) in the treatment of chronic lumbar disc herniation (CLDH) [14,7,19,24,4], where reduction of pain intensity and improvement in activities of daily living were found, in addition to studies of chronic LBP treated by CSE as the pain and functional disability were reduced[2,28,23,12].

Core Stabilization Exercise (CSE) also might be beneficial for patients with chronic LBP, CSE alone might not be sufficient for best improvement in patients with serious physical limitations to functional recovery [29]. It has been recommended that the combination of SDT and other treatment protocols would be useful for patients with discogenic LBP [2,20,9].

Al-Qudah \& Al-Jazzazi [2] studied the effect of CM and modified SDT (Combined Lumbar Traction With Cervical Traction) with CSE in patients with Lumbar bulging disc, Significant improvement in pain and daily ability were found after 6 weeks. Gaowgzeh, et al. [13] studied the effect of SDT via DRX9000TM device and CSE with Interferential current (IFC) in patients with Lumbar disc prolapse, Significant improvement in pain and disability were found after 6 weeks. Asiri, et al [8] applied SDT via specific three dimensional lumbar traction device on 25 patients with Lumbar Intervertebral Disc Prolapse, Significant improvement in pain, pain pressure threshold and functional disability was found after 4 weeks. Kim \& Yun \& Huh [17] studied 35 patients with lumbosacral disc herniation reported a significant reduction of pain on the visual analogue scale in the group who received SDT via DRX3000 compared to intermittent mechanical traction. The author concluded that patients with discogenic LBP, SDT can be used as an effective treatment without serious complications.

Bilgilisoy, et al. [10] compared two deferent positions of SDT, 118 patients with chronic Low Back Pain applied Supine Mechanical Lumbar traction or Prone Mechanical Lumbar traction, Significant improvement in pain, disability and range of motion were found after 3 weeks. Lee, et al. [18] compared two deferent types of SDT, Lumbar Lordotic curve controlled traction (L-LCCT) with traditional lumbar traction, 40 patients with Lumbar intervertebral Disc improved significantly in pain and disability after 5 weeks in both groups, where L-LCCT group relieved significant improvement, which suggests that pain relief can be related to the restoration of disc height for chronic discogenic LBP. Choi et al. [11] studied the effect of SDT and also compared it with general traction therapy on pain, functional capability, and straight leg raising of 30 patients with herniated lumbar disc 
who received three sessions per week for four weeks. Both groups have shown significant improvement and no statistically significant differences were found between the groups. As stated by the author, combining more treatments or increasing the duration might give different findings. In the present study, the duration of treatment in both groups was longer in addition to the CSE program.

The previous studies have examined Cupping Massage (CM) with or without several method of Spinal Decompression Therapy (SDT), SDT with or without Physiotherapy modalities, even with or without Core Stabilization Exercise (CSE). While the

current study examined the efficacy of Combined Lumbar Traction With Cervical Traction (CLTCT) as a new method of SDT, and compared CLTCT with Mechanical Lumbar Traction.

The findings of the current study show the positive effects of Combined Lumbar Traction With Cervical Traction (CLTCT) as one intervention in patients with CLDH. There were few limitations of the present study, including that long-term effects of the treatment were not obtained due to the limitation of time, also the exclusion of subjects with BMI over 30 who had extra structural-abdominal risk factors which may prolong treatment duration.

\section{5.}

\section{Conclusions}

A Combination of Lumbar Traction With Cervical Traction (CLTCT) as one intervention has proven to be more significant when compared with traditional Mechanical Lumbar Traction to reduce pain and disability in subjects with chronic Lumbar Disc Herniation. The researcher recommend MRI for future studies, where it could be used as a post intervention assessment tool, which will warrant robust measurement of the vertical mechanical displacement along the longitudinal axes of the spinal column, and the mechanical displacement of the affected disc. Also, the researcher recommend the use of CLTCT via any other available traction devices.

\section{References}

1. Al-Khararbah, S. (2018). Impact Of Dry Cupping On Non-specific Low Back Pain-Muscular Spasm Origin- Among Sport Science Collage Students. Unpublished Master Thesis, Mutah University, AlKarak, Jordan.

2. Al-Qudah, M.K. \& Al-Jazzazi, S.A. Impact Of Cupping Massage and Modified Spinal Decompression Therapy With Core Stabilization Exercise In Lumbar Bulging Disc Management. PSYCHOLOGY AND EDUCATION (2021) 58(3):1978-1986.

3. Al-Qudah, M.K. \& Al-Jazzazi, S.A. Impact Of Rehabilitative Program On Patients With Low Back Pain - Muscular Origin Among Sports Science Collage Students In Mutah University - Jordan. PSYCHOLOGY AND EDUCATION (2021) 58(2): 10056-10066.

4. Al-Qudah, M. \& Bani Hani. (2013). Effect of therapeutic exercises in the rehabilitation of chronic cartilage hernia. Journal of Studies (Derasat) of the University of Jordan, Volume (40) Educational Sciences, Supplement (4)June.

5. Al-Qudah, M. The effect of a proposed program of therapeutic exercises on patients with chronic low back pain. Mutah Lil-Buhuth wad-Dirasat, 2011,26(6).

6. Alrwaily, M; Almutiri, M; Schneider, M. Assessment of variability in traction interventions for patients with low back pain: a systematic review. Chiropractic \&Manual Therapies, volume 26, Article number: 35(2018). https://chiromt.biomedcentral.com/articles/10.1186/s12998-018-0205-z

7. Apfel CC, Cakmakkaya OS, Martin W, Richmond C, Macario A, George E, et al. Restoration of disk height through nonsurgical spinal decompression is associated with decreased discogenic low back pain: a retrospective cohort study. BMC MusculoskeletDisord. 2010; 11(1):155.

8. Asiri, F; Tedla, JS; Alshahrani, MS. D; Ahmed, I; Reddy, RS; Gular, K. Effects of patient-specific three-dimensional lumbar traction on pain and functional disability in patients with lumbar intervertebral disc Prolapse. Nigerian Journal of Clinical Practice, Year 2020, Volume 23, Issue 4 [p. 498-502]

DOI: 10.4103/njcp.njcp_285_19 PMID: 32246656.

9. Beattie PF, Nelson RM, Michener LA, Cammarata J, Donley J. Outcomes after a prone lumbar traction protocol for patients with activity-limiting low back pain: a prospective case series study. Arch Phys Med Rehabil. 2008; 89(2): 269-74.

10. Bilgilisoy,FM;Kiliç,Z;Uçkun,A;ÇakirT,Kolda,DS;Toraman,NF.MechanicalTractionfor 
Lumbar Radicular Pain: Supine or Prone? A Randomized Controlled Trial. Am J Phys Med Rehabil. 2018 Jun;97(6):433-439. https://pubmed.ncbi.nlm.nih.gov/29309314/

11. Choi J, Lee $S$, Hwangbo G. Influences of spinal decompression therapy and general traction therapy on the pain, disability, and straight leg raising of patients with intervertebral disc herniation. J Phys Ther Sci. 2015; 27(2):481-3.

12. Ganiyu SO, Gujba KF. Effects of acupuncture, core-stability exercises, and treadmill walking exercises in treating a patient with postsurgical lumbar disc herniation: a clinical case report. JAMS J Acupunct Meridian Stud. Elsevier Korea LLC. 2015; 8(1):48-52.

13. Gaowgzeh, R, M; Chevidikunnan, M,F; BinMulayh, I A; Khan, F. Effect of spinal decompression therapy and core stabilization exercises in management of lumbar disc prolapse: A single blind and randomized controlled trial. Journal of Back and Musculoskeletal Rehabilitation; 33 (2020) 225-231. DOI 10.3233/BMR-171099 . IOS Press.https://pubmed.ncbi.nlm.nih.gov/31282394/

14. Gionis T, Groteke E. Clinical outcomes for spinal decompression. Orthop TechnolRev. 2003; 5:5-6.

15. Hayashi,Y.(2004).PhysicalTherapyforLowBackPain.JMAJ47(5)p:234-239.

16. Hong, Y; Wu, J; Wang, B. (2006). The effect of moving cupping therapy on nonspecific low back pain. Chinese Journal of Rehabilitation Medicine 21(3):340-343.

17. Kim HS, Yun DH, Huh KY. Effect of spinal decompression therapy compared with intermittent mechanical traction in lumbosacral disc herniation. J Korean Acad Rehabil Med. Korean Academy of Rehabilitation Medicine. 2008; 32(3):319-23.

18. Lee, CH; Heo, SJ; Park, SH; Jeong, HS; Kim, SY. Functional Changes inPatients and Morphological Changes in the Lumbar Intervertebral Disc after ApplyingLordotic Curve-Controlled Traction: A Double-Blind Randomized Controlled Study. J.Medicina (Kaunas). 2019 Dec 19;56(1):4 . https://pubmed.ncbi.nlm.nih.gov/31861714/

19. Macario A, Pergolizzi JV. Systematic literature review of spinal decompression via motorized traction for chronic discogenic low back pain. Pain Pract. 2006; 6(3): 171-8.

20. Macario A, Richmond C, Auster M, Pergolizzi JV. Treatment of 94 outpatients with chronic discogenic low back pain with the DRX9000: a retrospective chart review. Pain Pract. 2008; 8(1): 117.

21. MacDonald DA, Moseley GL, Hodges PW. The lumbar Multifidus: does the evidence support clinical beliefs? Man Ther. 2006; 11(4):254-63.

22. Manchikanti L, Abdi S, Atluri S, Benyamin RM, Boswell MV, Buenaventura RM, et al. An update of comprehensive evidence-based guidelines for interventional techniques in chronic spinal pain. Part II: guidance and recommendations. Pain Physician. 2013; 16(2 Suppl):S49-283.

23. Muthukrishnan R, Shenoy SD, Jaspal SS, Nellikunja S, Fernandes S. The differential effects of core stabilization exercise regime and conventional physiotherapy regime on postural control parameters during perturbation in patients with movement and control impairment chronic low back pain. Sports Med Arthrosc Rehabil Ther Technol. 2010; 2:13.

24. Owies, R; Mujalli, M. (2018). The Effect Of A Proposed Program Of Therapeutic Exercise In The Treatment Of Patients With Slipped Disc In The Lumbar Region. Jordanian Educational Journal,Volume (3), No (2),Article (3), P;48-66.

25. Pei-changXU; Shu-liCUI; Derrik, A.w; Chen,W;ShengXU; Lee, T. (2014). Preliminary observation on effect of cupping on the skin surface temperature of patients with back pain. World Journal of Acupuncture - Moxibustion, Volume 24, Issue4,30 December 2014, Pages 59-61. https://www.sciencedirect.com/science/article/abs/pii/S1003525715600307

26. Puntumetakul R, Areeudomwong P, Emasithi A, Yamauchi J. (2013).Effect of 10-week core stabilization exercise training and detraining on pain-related outcomes in patients with clinical lumbar instability. Patient Prefer Adherence. 2013; 7:1189-99.

27. Saha, F.J; Schumann, S; Cramer, H; Hohmann, C; Choi, K.-E; Rolke, R; Langhorst, J; Rampp, T; Dobos, G; Lauche, R. (2017). The Effects Of Cupping Massage In Patients With Chronic Neck Pain A Randomized Controlled Trial. Complement Med Res2017;24:26-32. https://www.karger.com/Article/Fulltext/454872

28. Salavati M, Akhbari B, Takamjani IE, Bagheri H, Ezzati K, Kahlaee AH. Effect of spinal stabilization exercise on dynamic postural control and visual dependency in subjects with chronic nonspecific low back pain. J Bodyw Mov Ther. 2016; 20 (2):441-8.

29. Standaert CJ, Weinstein SM, Rumpeltes J. Evidence-informed management of chronic low back pain with lumbar stabilization exercises. Spine J. 2008; 8(1):114-20. 